\title{
Ferroelectric Thin-Film Capacitors and Piezoelectric Switches for Mobile Communication Applications
}

\author{
Mareike Klee, Harry van Esch, Wilco Keur, Biju Kumar, Linda van Leuken-Peters, Jin Liu, Rüdiger \\ Mauczok, Kai Neumann, Klaus Reimann, Member, IEEE, Christel Renders, Aarnoud L. Roest, \\ Mark P. J. Tiggelman, Marco de Wild, Olaf Wunnicke, and Jing Zhao
}

(Invited Paper)

\begin{abstract}
Thin-film ferroelectric capacitors have been integrated with resistors and active functions such as ESD protection into small, miniaturized modules, which enable a board space saving of up to $80 \%$. With the optimum materials and processes, integrated capacitors with capacitance densities of up to $100 \mathrm{nF} / \mathrm{mm}^{2}$ for stacked capacitors combined with breakdown voltages of $90 \mathrm{~V}$ have been achieved. The integration of these high-density capacitors with extremely high breakdown voltage is a major accomplishment in the world of passive components and has not yet been reported for any other passive integration technology. Furthermore, thin-film tunable capacitors based on barium strontium titanate with high tuning range and high quality factor at $1 \mathrm{GHz}$ have been demonstrated. Finally, piezoelectric thin films for piezoelectric switches with high switching speed have been realized.
\end{abstract}

\section{INTRODUCTION}

$\mathrm{F}$ ERroelectric and piezoelectric thin films are gaining more importance for the integration of high-performance functions in miniaturized modules. Dielectric, ferroelectric, and piezoelectric thin films are excellently suited to realize system in package $(\mathrm{SiP})$ devices, which are multifunctional modules, where individual functions are implemented in their optimum technology with respect to performance, size, and cost. SiP especially plays a role for devices based on nontraditional materials and processes, which are not available in standard CMOS technologies (more than Moore) and is thus a complementary technology to the system-on-chip, which follows the CMOS roadmap as predicted by Moore's law. Small-sized SiP making use of ferroelectric thin films will be discussed.

\section{Integrated, Discrete Modules With High- Performance Integrated Passives}

\section{A. Devices and Processes}

Integration of passive functions with active functions into miniaturized modules is a prerequisite for next-generation

Manuscript received August 18, 2008; accepted December 10, 2008. This work was supported in part by the EU project NANOSTAR.

M. Klee, H. van Esch, W. Keur, B. Kumar, R. Mauczok, C. Renders, and M. de Wild are with Philips Research, Eindhoven, the Netherlands (e-mail: mareike.klee@philips.com).

L. van Leuken-Peters, J. Liu, K. Neumann, K. Reimann, A. L. Roest, O. Wunnicke, and J. Zhao are with NXP Semiconductors Coorporate I\&T, Eindhoven, the Netherlands (e-mail: aarnoud.roest@nxp.com).

M. Tiggelman is with the UT Utwente, MESA+ Research Institute for Nanotechnology, Enschede, the Netherlands.

Digital Object Identifier 10.1109/TUFFC.2009.1213 base-band, audio, and power circuits of mobile and portable electronic systems. We have opened the way for integrated passive functions such as capacitors and resistors with active functions like electrostatic discharge (ESD) protection diodes into one integrated module [1], [2]. This integration of ferroelectric capacitors with resistors and ESD protection diodes in a small chip-scale package enables a board space saving of up to $80 \%$ (see Fig. 1).

The devices are realized on highly doped silicon substrates. With optimum design and processing, Zener diodes for ESD protection of 8,12 , and $16 \mathrm{kV}$ are integrated. The ESD protection is essential in mobile and portable circuits to protect downstream ICs from electrostatic discharge. On top of the Si substrate, thin-film metal-insulator-metal (MIM) capacitors are integrated together with thin-film resistors. MIM capacitors offer high design flexibility. Floating coupling capacitors and shunt capacitors can be integrated next to resistors and ESD protection diodes (see Fig. 2).

The thin film MIM capacitors, which are integrated with active functions, are based on lead titanate zirconate. The films are processed on top of $\mathrm{Ti} / \mathrm{Pt}$ electrodes by spin-on technology. The ferroelectric thin films have a typical thickness of 270 to $400 \mathrm{~nm}$. On top of the ferroelectric thin films, thin-film metal layers are deposited and lithographically patterned. They enable the processing of resistors of $50 \Omega$ up to several hundred kilo-ohms. A special feature of the integration process is that not only ferroelectric MIM capacitors have been integrated with resistors and ESD protection diodes.

In an extension of the process technology, stacking of the ferroelectric capacitors on top of each other also has been realized. The stacking and connecting in parallel enables, on the one hand, a strong increase of the capacitance density of the MIMIM thin-film integrated capacitors. On the other hand, it offers a 3-D integration and an extremely high integration density. An example of stacked ferroelectric MIMIM capacitors on top of Si substrates with integrated active functions is shown in Figs. 3 and 4. The combination of 3 transmission electron microscopy (TEM) dark field images (in red, green, and blue) highlights the columnar growth of the ferroelectric thin films with (lateral) column widths in the range 100 to $300 \mathrm{~nm}$.

Thin-film capacitors realized in the first generation devices have a typical dielectric thickness of 270 to $400 \mathrm{~nm}$, 


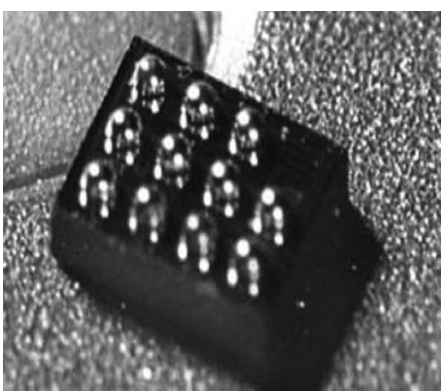

Fig. 1. High-density metal-insulator-metal (MIM) capacitors integrated with resistors and ESD protection diodes in small chip-scale package.
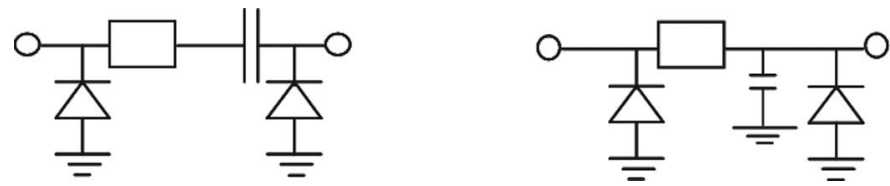

Fig. 2. High-density MIM capacitors designed to ground (right schematic) and in/out (left schematic) integrated with resistors and ESD protection diodes.

relative permittivities of 850 to $1050, \tan \delta$ of $\sim 1.5 \%$, and capacitance densities of 23 to $30 \mathrm{nF} / \mathrm{mm}^{2}$. These firstgeneration thin-film capacitors integrated with resistors and ESD protection diodes offer high-performance products, comprising, for example, low pass filters with ESD protection diodes (see Fig. 5).

By modification of the process and stacking of 2 capacitors on top of each other, integrated thin-film capacitors have been achieved that show relative permittivities of up to 1600 and capacitance densities of 80 to $100 \mathrm{nF} / \mathrm{mm}^{2}$.

Stacking of thin-film capacitors has been demonstrated by other groups for $\mathrm{Ba}_{1-\mathrm{x}} \mathrm{Sr}_{\mathrm{x}} \mathrm{TiO}_{3}$ thin films [3] as well as for lanthanum-doped $\mathrm{PbZr}_{x} \mathrm{Ti}_{1-x} \mathrm{O}_{3}$ films. Stacked PLZT capacitors, applying extremely thin PLZT (12/30/70) films with $50 \mathrm{~nm}$ thickness to achieve high capacitances of up to $500 \mathrm{nF}$, have been reported in [4].

\section{B. Quality and Reliability of Integrated Discrete Modules with Ferroelectric Capacitors}

The capacitors developed in our process show an extremely high capacitance density and extremely high breakdown voltages. For the thin-film capacitors with capacitance densities of $20 \mathrm{nF} / \mathrm{mm}^{2}$ and thickness of $400 \mathrm{~nm}$, a relative permittivity of 950 and a breakdown voltage of $140 \mathrm{~V}$, corresponding with a breakdown field of $3.5 \mathrm{MV} /$ $\mathrm{cm}$, is obtained. Breakdown voltages were obtained from measurements of the current as a function of voltage with increasing voltage rate with $5 \mathrm{~V} / \mathrm{s}$. Breakdown voltage is determined from the point where the current strongly increases by orders of magnitude while increasing the voltage with $5 \mathrm{~V} / \mathrm{s}$.

Literature models predict a decrease of the breakdown field $\left(E_{\mathrm{bd}}\right)$ as a function of the dielectric constant $k$ $\left(E_{\mathrm{bd}} \sim k^{-0.5}\right)$ [5], [6], which makes it challenging to combine high-capacitance densities with a high-breakdown

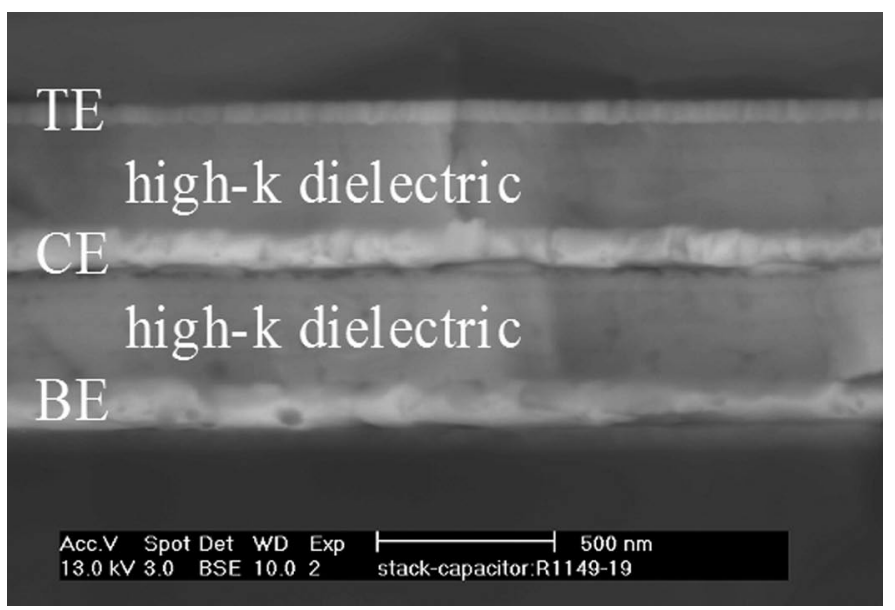

Fig. 3. SEM micrograph of a stacked ferroelectric capacitor: The cross section shows 2 layers with high relative permittivity sandwiched between the bottom electrode (BE) and the top electrode (TE) and a shared center electrode $(\mathrm{CE})$.

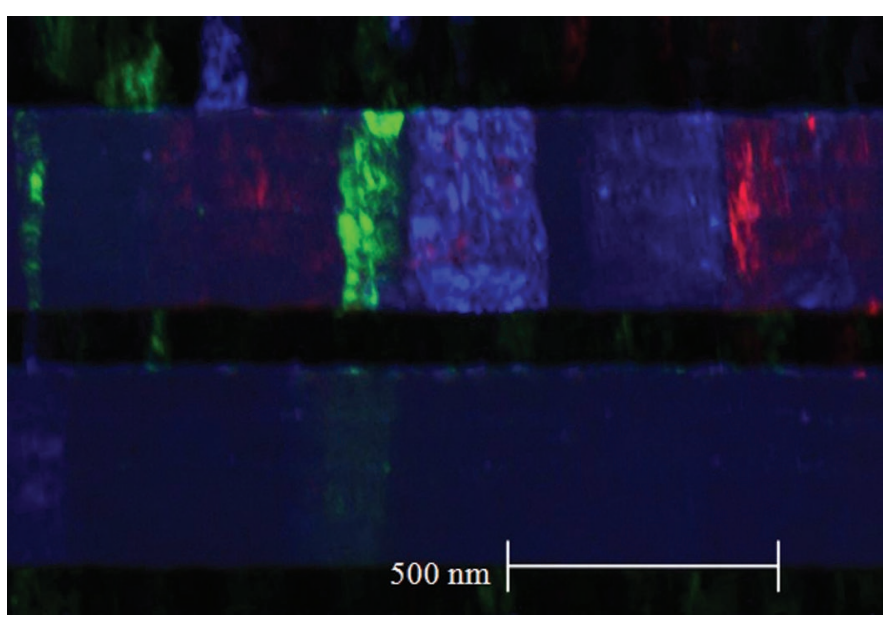

Fig. 4. Combination of 3 TEM dark field images of a stacked ferroelectric capacitor with high relative permittivity. The high- $k$ layers are sandwiched between the bottom electrode $(\mathrm{BE}, \mathrm{Ti} / \mathrm{Pt})$, the top electrode (TE, resistor metal), and a shared center electrode $(\mathrm{CE}, \mathrm{Pt})$.

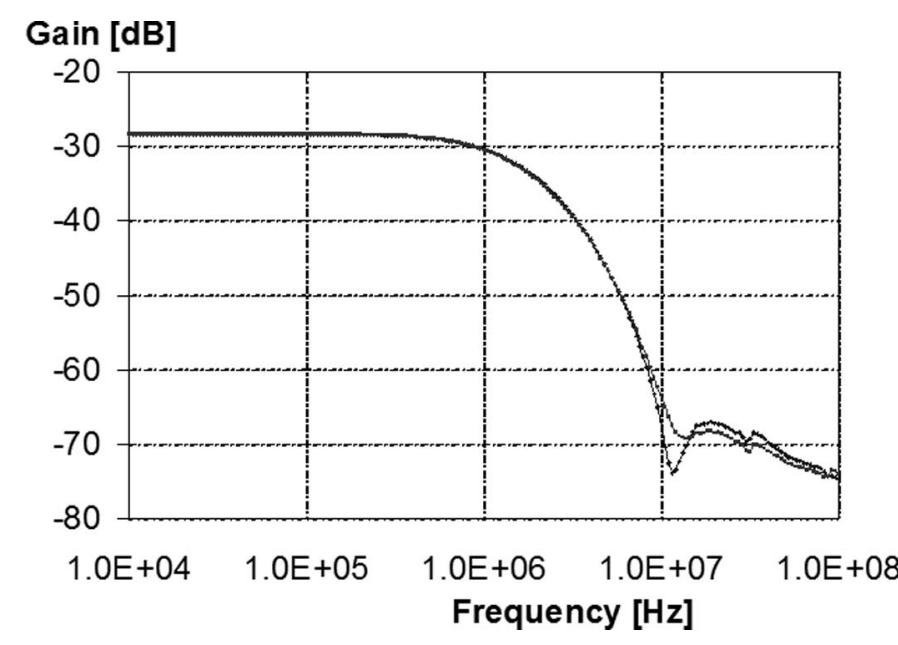

Fig. 5. Frequency response of 2 RC low-pass filters with high density MIM capacitors integrated in Si substrate next to ESD protection diodes. 


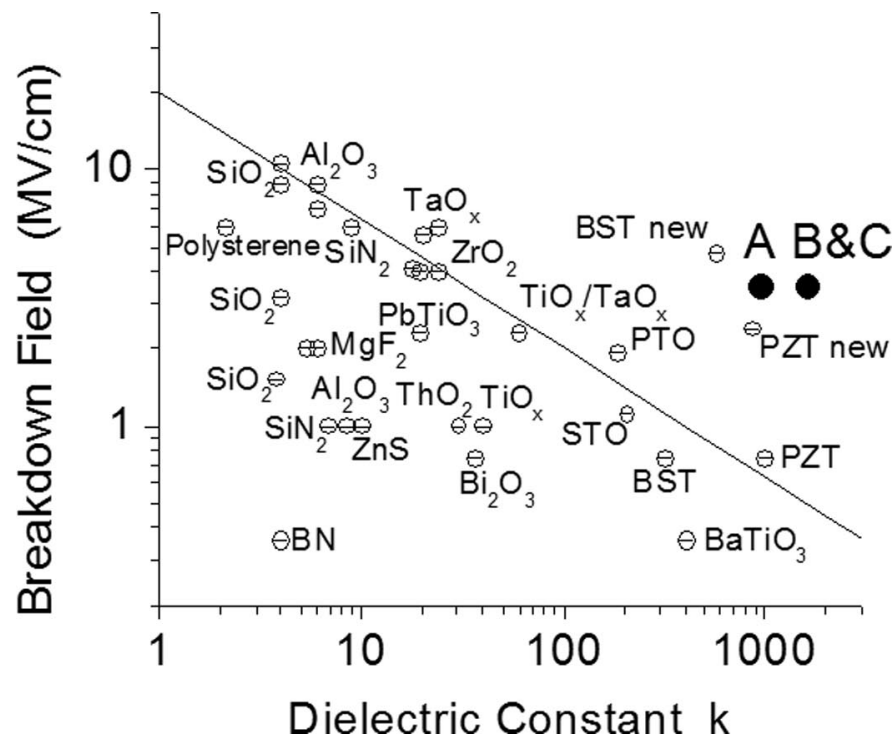

Fig. 6. The breakdown field $\left(E_{\mathrm{bd}}\right)$ as a function of the dielectric constant $(k)$. The breakdown field decreases as the dielectric constant increases. The line is a fit through the data of the best samples from literature, obtained from [5]. Two more recent data points are added from [6] and [7] indicated by "new." The results from our work are indicated by the black circles ( ) The details of A, B, and C can be found in Table I.

voltage $\left(U_{\mathrm{bd}}\right)$. However, these models are mainly based on paraelectric materials. First-generation devices with a capacitance density of $20 \mathrm{nF} / \mathrm{mm}^{2}$ and a $U_{\mathrm{bd}}$ of $140 \mathrm{~V}$ are currently mass-produced at NXP Semiconductors. The $E_{\mathrm{bd}}$ of these capacitors, $3.5 \mathrm{MV} / \mathrm{cm}$, is considerably larger than what is estimated in [5] and [6], $(\sim 0.6 \mathrm{MV} / \mathrm{cm}$ for $k$ $=950$, see Fig. 6).

The model from [5] is a phenomenological model, based on the best data from literature. In [6], the interpretation of the results is based on a calculation of the breakdown strength by a thermochemical model. Our results demonstrate that ferroelectric materials are able to outperform the estimations from [5] and [6]. The high breakdown field of $3.5 \mathrm{MV} / \mathrm{cm}$ of our ferroelectric thin film capacitors is in the order of breakdown fields reported for $\mathrm{TiO}_{2}$ thin films, but at much higher relative permittivities of up to 1600 in contrast to approximately 80 to 100 for $\mathrm{TiO}_{2}$. This enables the integration of very large capacitors with high breakdown voltages above $50 \mathrm{~V}$ in Si technology. The high breakdown voltage is requested for numerous consumer applications. Currently, due to the limitations of the capacitance density in Si-processing, large capacitors with high breakdown voltage are typically mounted as discrete SMD components on the printed circuit board, consuming more area than the integrated solution with high-density capacitors.

To offer even higher capacitance densities than $20 \mathrm{nF} /$ $\mathrm{mm}^{2}$, stacked capacitors with $360 \mathrm{~nm}$ and $270 \mathrm{~nm}$ thickness and relative permittivities of 1600 are realized, which show capacitance densities of $80 \mathrm{nF} / \mathrm{mm}^{2}$ and $100 \mathrm{nF} /$ $\mathrm{mm}^{2}$. For these integrated capacitors, breakdown voltages of 120 and $90 \mathrm{~V}$ were achieved, which correspond to a breakdown field of $3.3 \mathrm{MV} / \mathrm{cm}$.

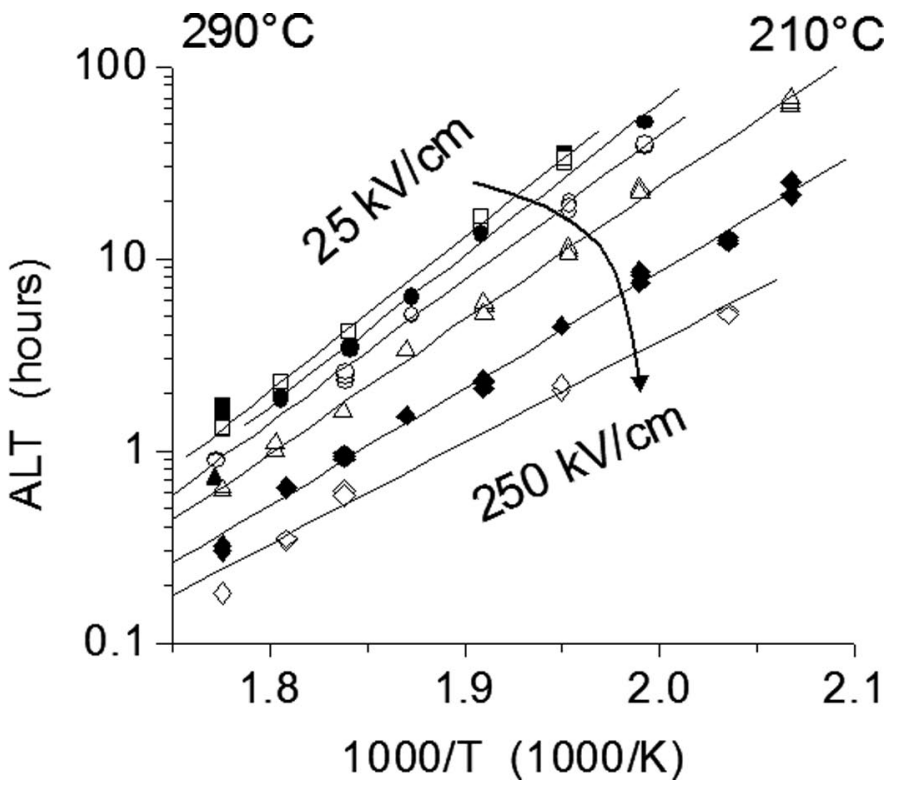

Fig. 7. Accelerated lifetime results for the high- $k$ capacitors of type A $\left(20 \mathrm{nF} / \mathrm{mm}^{2}\right)$. Measurements are performed between 290 and $210^{\circ} \mathrm{C}$ and from 25 to $250 \mathrm{kV} / \mathrm{cm}$. The data are fitted by an Arrhenius law, $t \sim$ $\exp \left(E_{\text {act }} / k T\right)$.

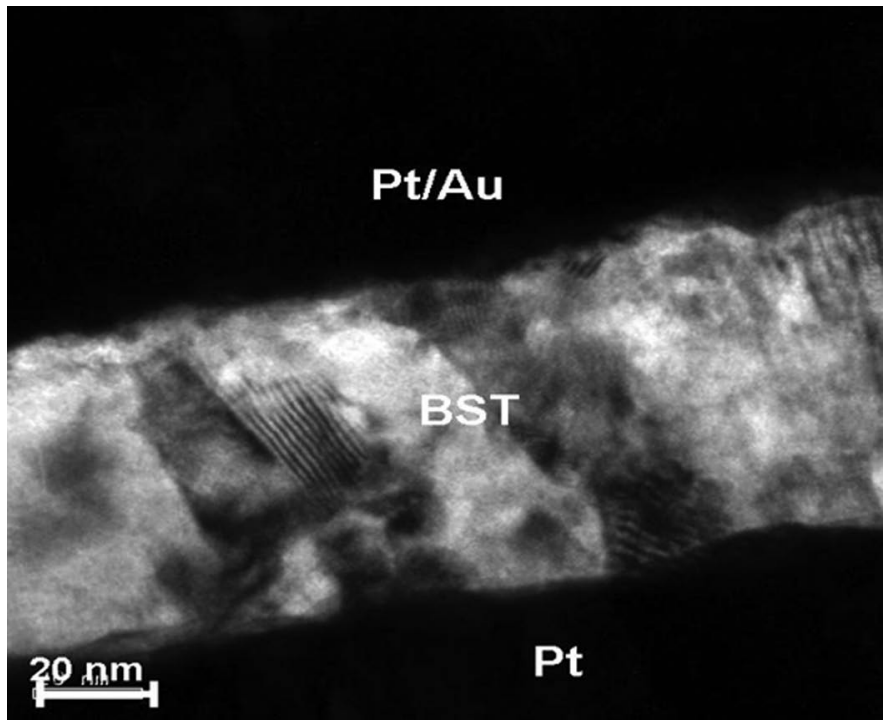

Fig. 8. TEM image of a $\mathrm{Ba}_{1-x} \mathrm{Sr}_{x} \mathrm{TiO}_{3}$ thin film grown on top of a $\mathrm{Pt}$ bottom electrode.

The extremely high-capacitance density of $100 \mathrm{nF} /$ $\mathrm{mm}^{2}$ for the integrated thin-film capacitor and the high breakdown voltage of $90 \mathrm{~V}$ is a revolution in the world of integration of passive components and has not yet been reported for any other passive integration technology.

The devices are developed for numerous applications, which require typical operation voltages of 3 to $5 \mathrm{~V}$ and lifetimes of 10 years at $85^{\circ} \mathrm{C}$. For this reason, we intensively investigated the lifetime of our capacitors under dc bias. Accelerated lifetime tests (ALT) have been applied to determine the lifetime of the various capacitors. The end of life of the capacitors was defined as the time where the leakage current has been increased by one order of magnitude, which is a much more conservative lifetime 
TABle I. Extrapolated Lifetime for Integrated Ferroelectric Capacitors.

\begin{tabular}{|c|c|c|c|c|c|}
\hline Type & $\begin{array}{c}\mathrm{C} / \mathrm{A} \text { in } \\
\mathrm{nF} / \mathrm{mm}^{2}\end{array}$ & $\begin{array}{l}d \text { in } \\
\mathrm{nm}\end{array}$ & Capacitor & $\begin{array}{c}\text { Effective } \\
\text { dielectric } \\
\text { constant }(k)\end{array}$ & $\begin{array}{c}\text { ALT at } 5 \mathrm{~V} \\
\text { and } 85^{\circ} \mathrm{C} \\
\text { in years }\end{array}$ \\
\hline A & 20 & 400 & single & 950 & 1500 \\
\hline B & 80 & 360 & stacked & 1600 & 70 \\
\hline $\mathrm{C}$ & 105 & 270 & stacked & 1600 & 13 \\
\hline
\end{tabular}

${ }^{1} \mathrm{ALT}=$ accelerated lifetime test.

definition than the lifetimes obtained by time-dependent breakdown measurements. The field dependence of the lifetime for $20 \mathrm{nF} / \mathrm{mm}^{2}$ (area is $0.5 \mathrm{~mm}^{2}$ ) capacitors at elevated temperatures of 210 to $290^{\circ} \mathrm{C}$ has been studied. On an Arrhenius plot, lifetime versus 1/T, an exponential behavior $t \sim \exp \left(E_{\text {act }} / k T\right)$ with a field-dependent activation energy, $E_{\text {act }}$, of 1.6 to $1.1 \mathrm{eV}$ for 75 to $250 \mathrm{kV} / \mathrm{cm}$ has been determined (see Fig. 7).

Extrapolation of the lifetime to $85^{\circ} \mathrm{C}$ results in more than 10 years' lifetime for capacitors with $20 \mathrm{nF} / \mathrm{mm}^{2}$ and for voltages as high as $10 \mathrm{~V}(250 \mathrm{kV} / \mathrm{cm})$ (see Table I).

Besides the lifetime data for $20 \mathrm{nF} / \mathrm{mm}^{2}$ capacitors, we also studied the lifetime of 80 and $100 \mathrm{nF} / \mathrm{mm}^{2}$ capacitors (area is $0.3 \mathrm{~mm}^{2}$ ). The lifetime at $85^{\circ} \mathrm{C}$ and $5 \mathrm{~V}$ for stacked capacitors with $80 \mathrm{nF} / \mathrm{mm}^{2}$, processed from $370 \mathrm{~nm}$ thick dielectrics with relative permittivities of 1600, has been extrapolated down from high temperature data. For $80 \mathrm{nF} / \mathrm{mm}^{2}$ stacked capacitors, lifetimes of 70 years at $5 \mathrm{~V}$ and $85^{\circ} \mathrm{C}$ have been determined. For stacked capacitors with a $270 \mathrm{~nm}$ thick dielectric layer with a relative permittivity of 1600 and $100 \mathrm{nF} / \mathrm{mm}^{2}$, a lifetime of 13 years at $85^{\circ} \mathrm{C}$ and $5 \mathrm{~V}$ has been extrapolated. These data show that the integrated capacitors developed here with capacitance densities of 20 to $100 \mathrm{nF} / \mathrm{mm}^{2}$ offer at operating voltages of $5 \mathrm{~V}$ and operating temperatures of up to $85^{\circ} \mathrm{C}$ a lifetime of more than 10 years.

\section{Integrated Tunable Capacitors for Matching Networks AND Tunable Filters}

Tunable capacitors based, e.g., on paraelectric thin films with perovskite or pyrochlore lattice are becoming more relevant for miniaturized adaptive impedance matching networks, tunable filters, voltage controlled oscillators, or phase shifters [8]-[10]. $\mathrm{Ba}_{1-x} \mathrm{Sr}_{x} \mathrm{TiO}_{3}$ (BST) thin films with $x=0$ to 1 [11], [12], as well as $\mathrm{Bi}_{1.5} \mathrm{Zn}_{1.0} \mathrm{Nb}_{1.5} \mathrm{O}_{7}$ [14], are investigated. For $\mathrm{Ba}_{1-x} \mathrm{Sr}_{x} \mathrm{TiO}_{3}$ thin films with $x=0.5$, which are deposited by sputtering with a typical thickness of 100 to $150 \mathrm{~nm}$ on sapphire substrates - and depending on the sputter conditions - relative permittivities of 300 to 900 at $0 \mathrm{~V}$ bias and maximum tuning ranges of $90 \%$ are reported above $3 \mathrm{MV} / \mathrm{cm}$ [11]. For these tunable capacitors, quality factors of 40 to 160 at $1 \mathrm{MHz}$ up to several gigahertz are reported.

Besides $\mathrm{Ba}_{1-x} \mathrm{Sr}_{x} \mathrm{TiO}_{3}, \quad \mathrm{Bi}_{1.5} \mathrm{Zn}_{1.0} \mathrm{Nb}_{1.5} \mathrm{O}_{7}$ thin films crystallizing in the pyrochlore phase are investigated for tunable capacitors [14]. Thin films with thickness of 300 to $330 \mathrm{~nm}$ are deposited by sputtering on glass substrates with a Ti/Pt electrode. Au-topped electrodes are applied on the dielectric thin film. Relative permittivities of 185 , tunability of $44 \%$ at $1 \mathrm{MV} / \mathrm{cm}$, and quality factors above $100 \mathrm{up}$ to $5 \mathrm{GHz}$ for capacitors with $64 \mu \mathrm{m}^{2}$ capacitance area are reported.

We have investigated $\mathrm{Ba}_{1-x} \mathrm{Sr}_{x} \mathrm{TiO}_{3}$ thin films with $x=0$ to 0.5 , which are deposited on Si-substrates with $\mathrm{Ti} / \mathrm{Pt}$ or $\mathrm{Pt}$ or $\mathrm{Pt} / \mathrm{Au} / \mathrm{Pt}$ metallic electrode layers. The barium strontium titanate thin films are grown by spinon processing at temperatures of 680 to $740^{\circ} \mathrm{C}$. As highly conductive top electrodes, $\mathrm{Au}$ or $\mathrm{Pt} / \mathrm{Au}$ electrodes are applied. All the layers are lithographically patterned using dry etching processes. The $\mathrm{Ba}_{1-\mathrm{x}} \mathrm{Sr}_{\mathrm{x}} \mathrm{TiO}_{3}$ thin films have a polycrystalline structure with a grain size varying from 20 to $40 \mathrm{~nm}$. For BST films grown on Ti/Pt bottom electrodes, a thin $\mathrm{TiO}_{2}$ dead interface layer at the Pt electrode was found with an EDAX (EDAX Inc., Mahwah, NJ) line profile analysis throughout the complete stack. Homogeneous dense films with a sharp Pt-BST interface could be processed on $\mathrm{Pt}$ electrodes without $\mathrm{Ti}$ adhesion layer (see Fig. 8). EDAX analysis (see Fig. 9) confirmed that no $\mathrm{TiO}_{2}$ interface layer between the BST film and the $\mathrm{Pt}$ electrode is formed.

With these thin films, having a typical thickness of 80 to $130 \mathrm{~nm}$, relative permittivities of 400 measured at $1 \mathrm{MHz}$ (using an HP4194a impedance analyzer; Hewlett Packard, Palo Alto, CA) to $5 \mathrm{GHz}$ (using an R3767CG vector network analyzer; Advantest Corporation, Tokyo, Japan) and corresponding to capacitance densities of $30 \mathrm{nF} / \mathrm{mm}^{2}$ and tuning ranges of $75 \%$ at $1 \mathrm{MHz}$ have been achieved. These high quality thin films grown on $\mathrm{Si}$ show at CMOS compatible operating voltages of $3 \mathrm{~V}$ already tunabilities of $35 \%$ (see Fig. 10) at $1 \mathrm{MHz}$. So with these thin films, tunabilities of $35 \%$ could be achieved at low voltages of $3 \mathrm{~V}$. This voltage is much lower than the maximum electrical field strength of the BST capacitors and enables therefore long lifetimes conditions for the capacitors.

At $1 \mathrm{GHz}$, the thin-film capacitors with BST thin film grown on top of a Pt-bottom electrode and a Pt/Au-top electrode show quality factors above 30 .

\section{Galvanic Piezoelectric Switches}

RF microelectromechanical system (MEMS) switches are attractive devices for mobile communication applications because they show lower insertion losses, higher iso- 


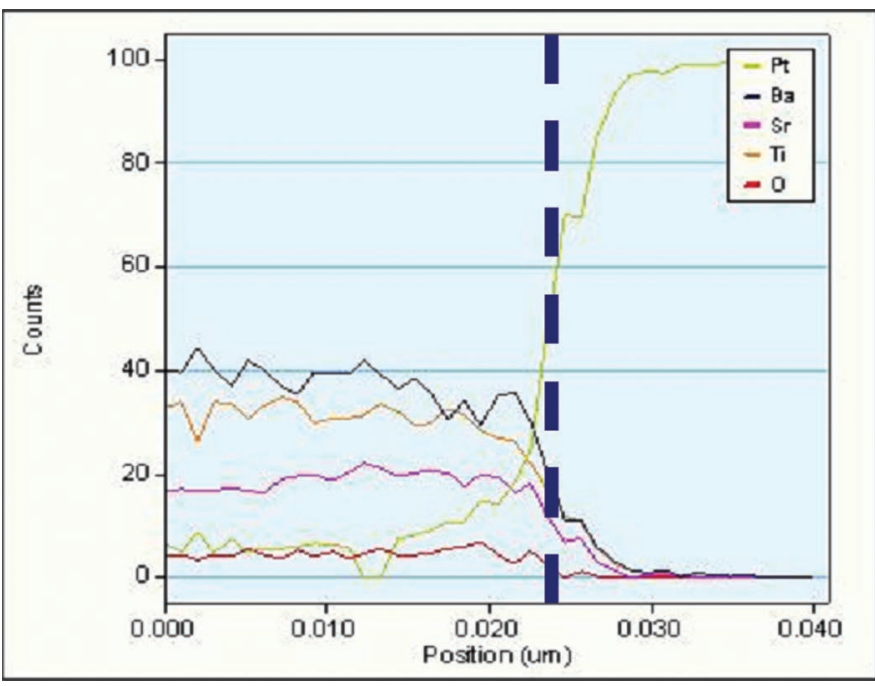

Fig. 9. EDAX analysis of the interface of the $\mathrm{Ba}_{1-x} \mathrm{Sr}_{x} \mathrm{TiO}_{3}$ thin film grown on top of a Pt bottom electrode.

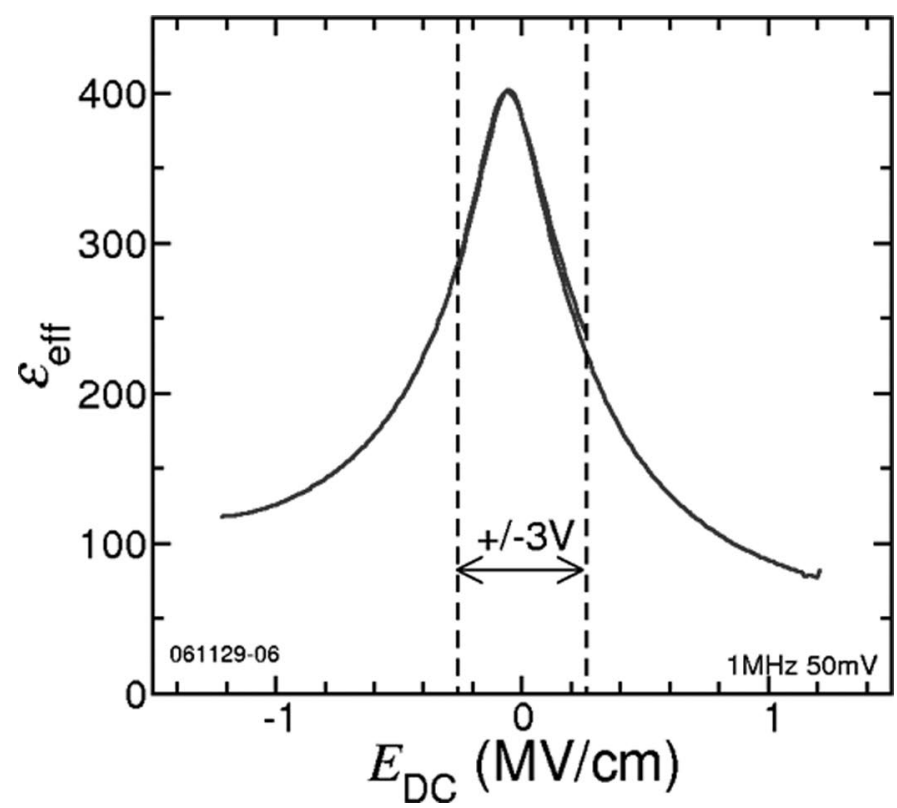

Fig. 10. Effective relative permittivity as a function of dc field for a $\mathrm{Ba}_{1-x} \mathrm{Sr}_{x} \mathrm{TiO}_{3}$ thin film grown on top of a $\mathrm{Pt}$ bottom electrode on $\mathrm{Si}$.

lations, and better linearity compared with currently used semiconducting RF switches like p-i-n diodes, pseudomorphic high electron mobility transistors (pHEMTs), or CMOS transistors. RF MEMS switches also have low power consumption, making them very suitable for mobile devices. Galvanic RF MEMS switches have been investigated by several groups, because they are broadband and have a higher RF isolation than capacitive MEMS switches.

We are investigating galvanic MEMS switches, based on piezoelectric actuators, which offer several advantages over electrostatic or thermal actuation. Piezoelectric actuators operate at lower voltage and possess a larger open gap and thus higher isolation in the open state. Piezoelectric galvanic switches are not yet state of the art. To

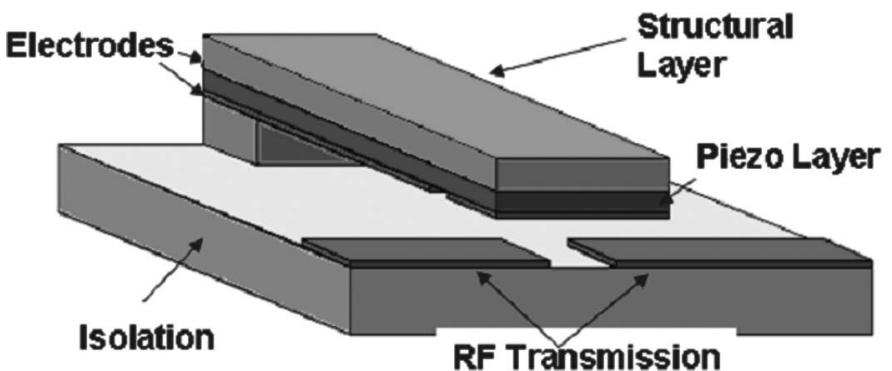

Fig. 11. Schematic picture of a galvanic piezoelectric microelectromechanical system switch. The structural layer is also used as the top electrode.

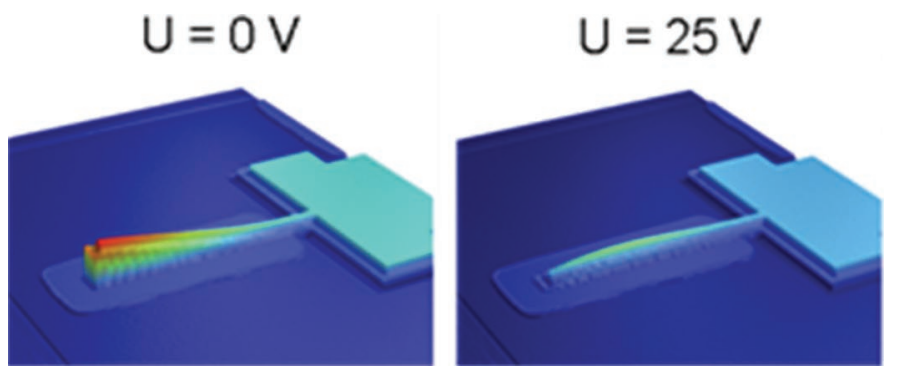

Fig. 12. White light interferometer measurement of the height profile of a galvanic piezoelectric microelectromechanical system switch.

benefit from their advantages, more research is needed with respect to actuator processing and optimum design [15]-[17].

An artist's view of the piezoelectric MEMS switch investigated in this work is shown in Fig. 11. The piezoelectric actuator is built up from a Ti/Pt bottom electrode. The piezoelectric layer is deposited using sol-gel processing. To realize galvanic MEMS switches, a low-temperatureprocessed 450 to $650^{\circ} \mathrm{C}$ lead titanate zirconate has been developed. In this design, the top electrode is also used as the structural layer to create a bending moment when applying a voltage across the piezoelectric layer.

The low-temperature-processed piezoelectric thin film materials used here yield a material coupling coefficient of $k_{33}^{t}=0.40 \pm 0.03$. It is slightly lower than the material coupling coefficient, which we achieved with our high temperature, processed lead titanate zirconate. For randomly oriented PZT material, coupling coefficients of $k_{33}^{t}=0.43$ \pm 0.03 were measured. For strongly (001)-oriented films, material coupling coefficients of $k_{33}^{t}=0.57 \pm 0.03$ were obtained.

The low-temperature-processed PZT that is applied in these piezoelectric switches shows high breakdown fields of $1.5 \mathrm{MV} / \mathrm{cm}$, low leakage currents of $10^{-10} \mathrm{~A} / \mathrm{mm}^{2}$ at room temperature, and $0.25 \mathrm{MV} / \mathrm{cm}$. Based on accelerated lifetime measurements (see above section on high$\mathrm{k}$ integrated devices) extrapolated lifetimes at $85^{\circ} \mathrm{C}$ and $0.25 \mathrm{MV} / \mathrm{cm}$ of more than 25 years have been determined. These data demonstrate that the piezoelectric thin-film materials applied here for piezoelectric switches show excellent piezoelectric properties as well as excellent dielectric reliability. 


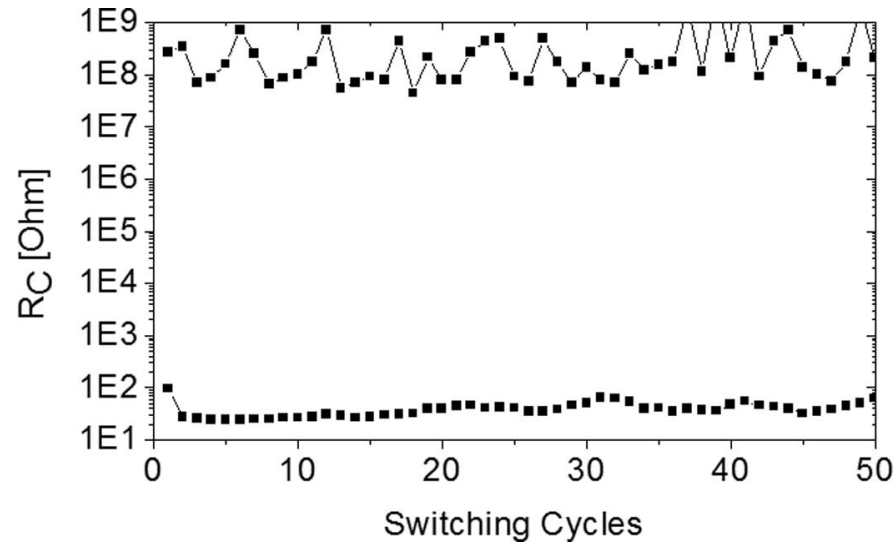

Fig. 13. Contact resistance in the closed and in the open state for 50 switching cycles.

In Fig. 12, a 3-D height distribution of a processed switch is shown. The picture is taken by means of a white light interferometer. Because of a gradient in the residual stress of the layers, the tip of the cantilever is pointing upward by several microns. On the left, the operating voltage is switched off and the contacts are open. When applying $25 \mathrm{~V}$ across the PZT (right plot), the switch closes and an electric contact is made. These piezoelectric thin film switches have also been tested with respect to their mechanical reliability and showed more than $10^{6}$ switching cycles without mechanical degradation.

In Fig. 13, the open and closed contact resistances are shown for 50 switching cycles. The actuation voltage is $30 \mathrm{~V}$ and the voltage across the galvanic contacts is $0.5 \mathrm{~V}$. As can be seen, the contact resistance varies. More detailed investigations are carried out on the contract resistance as a function of processing and design.

In Fig. 14, the measured tip deflection is compared with simulation results with good agreement. Because the residual stress gradient of this switch is smaller than the one in Fig. 12, the opening gap is smaller and hence the contact is already closed at $15 \mathrm{~V}$. The simulations are based on the 1-D Euler-Bernoulli bean equation for an inhomogeneous layer stack. To fit the measured data, a piezoelectric constant of $d_{31} E=-4 \mathrm{C} / \mathrm{m}^{2}$ was used with $E$ being the Young's modulus of the PZT layer. Further investigations are ongoing.

Making use of stroboscopic measurements, the mechanical opening and closing switching times have been determined for our thin-film piezoelectric switches on several devices. The opening gap of several switches is closed in less than $10 \mu \mathrm{s}$ and fully opened within $30 \mu \mathrm{s}$. The electric contact is broken in less than $20 \mu \mathrm{s}$. Piezoelectric switches can be opened and closed very fast.

\section{Conclusion}

Ferroelectric thin-film devices based on lead titanate zirconate were investigated for integrated capacitors.

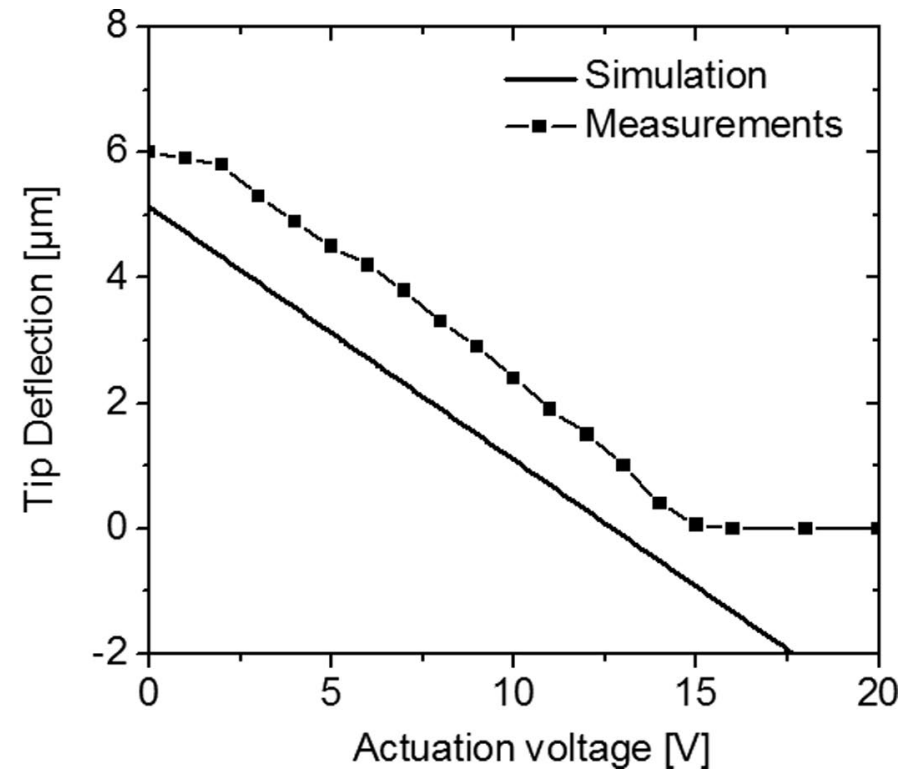

Fig. 14. Tip deflection of the piezoelectric switch for different operating voltages. Interferometric measurements (squares) and simulation results (solid line) are shown. At zero deflection contact is made. Note that no contact is included in the simulations.

They enable a new platform of integration of passive with active functions with integrated capacitors, resistors, and ESD protection diodes in small chip-scale package modules. These modules offer a board space saving of up to $80 \%$ and play an important role in present and future generation mobile communication systems. Capacitors with capacitance densities of 20 to $100 \mathrm{nF} / \mathrm{mm}^{2}$ and breakdown voltages of 90 to $150 \mathrm{~V}$ have been realized. For capacitance densities of more than $80 \mathrm{nF} / \mathrm{mm}^{2}$, stacked capacitors were used. These high-performance capacitors have been integrated with high-performance resistors and ESD protection diodes. These ferroelectric thin-film capacitors with high capacitance density of up to $100 \mathrm{nF} / \mathrm{mm}^{2}$ and high breakdown voltages of more than $90 \mathrm{~V}$ are a major accomplishment in the world of passive components and are not reported by any other passive integration technology. These capacitors offer lifetimes of more than 10 years at $5 \mathrm{~V}$ operating voltage and $85^{\circ} \mathrm{C}$. This new class of high$k$ integrated discrete devices is running in mass production at NXP Semiconductors.

Dielectric layers based on $\mathrm{Ba}_{1-x} \mathrm{Sr}_{x} \mathrm{TiO}_{3}$, which are processed on $\mathrm{Pt}$ electrodes on $\mathrm{Si}$, enable tunable capacitors with relative permittivities of 400 , more than $35 \%$ tuning at only $3 \mathrm{~V}$ and high quality factors above 30 at $1 \mathrm{GHz}$. These devices are attractive for adaptive impedancematching networks and tunable filters.

Piezoelectric thin films with high piezoelectric coupling coefficients and high breakdown voltages as well as excellent lifetimes are investigated for galvanic switches. Thinfilm switches with first-contact resistance measurements and high switching speeds of 5 to $20 \mu$ s have been demonstrated. Measured tip deflections are compared with analytical simulation results and show good agreement. 


\section{ACKNOWLEDGMENT}

Thanks are due to M. Vervest, J. van Berkum, M. Kaiser, H. Nulens, R. Bakker, P. Graat, H. Wondergem, and P. Rommers for the analytical studies of our thin films.

\section{REFERENCES}

[1] M. Klee, D. Beelen, W. Keur, R. Kiewitt, B. Kumar, R. Mauczok, K. Reimann, C. Renders, A. L. Roest, F. Roozeboom, P. Steeneken, M. Tiggelman, F. Vanhelmont, O. Wunnicke, P. Lok, K. Neumann, J. Fraser, and G. Schmitz, "Applications of dielectric, ferroelectric and piezoelectric thin film devices in mobile communication and medical systems," in Proc. IEEE Int. Symp. Applications of Ferroelectrics, 2006, pp. 9-16.

[2] M. Klee, U. Mackens, R. Kiewitt, G. Greuel, and C. Metzmacher, "Ferroelectric thin films for integrated passive components," Philips J. Res., vol. 51, pp. 363-387, 1998.

[3] M. M. Watt, P. Woo, T. Rywak, L. McNeil, A. Kassam, V. Joshi, J. D. Cuchiaro, and B. M. Melnick, "Feasibility demonstration of a multi-level thin film BST capacitor technology," in Proc. IEEE Int. Symp. Applications of Ferroelectrics (ISAF), 1998, pp. 11-14.

[4] B. Tuttle, G. L. Brennecka, C. M. Parish, L. N. Brewer, J. G. Ekerdt, and J. Wheeler, "Multilayer ultrathin film PLZT capacitors: Nanoscale materials issues," in Proc. Materials Research Soc. Symp., 2008, vol. 1034E, K6.1, pp. 176-181.

[5] P. Jain and E. J. Rymaszewski, "Embedded thin film capacitorstheoretical limits," IEEE Trans. Adv. Packag., vol. 25, pp. 454-458, Aug. 2002

[6] J. W. McPherson, J. Kim, A. Shanware, H. Mogul, and J. Rodriquez, "Trends in the ultimate breakdown strength of high dielectric-constant materials," IEEE Trans. Electron. Dev., vol. 50, pp. 1771-1778, Aug. 2003.

[7] E. Bouyssou, G. Guégan, S. Bruyère, R. Pezzani, L. Berneux, L. Dantas de Morais, J.-P. Rebrassé, C. Anceau, and C. Nopper, "Extended reliability study of high density PZT capacitors: Intrinsic lifetime determination and wafer level screening strategy," in Proc. IEEE 45th Annu. Int. Reliability Physics Symp., 2007, Phoenix, AZ, pp. $433-438$.

[8] I. Vendik, O. Vendik, V. Pleskachev, A. Svischchev, and R. Woerdenweber, "Design of tunable ferroelectric filters with a constant fractionalband width," IEEE MTT-S Dig., vol. 3, pp. 1461-1464, 2001.

[9] L. Y. V. Chen, R. Forse, D. Chase, and R. A. York, "Analog tunable matching network using integrated thin-film BST capacitors," IEEE MTT-S Digest, 2004

10] J. Nath, D. Ghosh, J.-P. Maria, A. I. Kingon, W. Fathelbab, P. D. Franzon, and M. B. Steer, "An electronically tunable microstrip bandpass filter using thin-film barium-strontium-titanate (BST) varactors," IEEE Trans. Microw. Theory Tech., vol. 53, no. 9, pp. 2707-2712, 2005.

[11] N. K. Pervez, P. J. Hansen, and R. A. York, "Optimization of high tunability barium strontium titanate thin films grown by RF magnetron sputtering," in Proc. IEEE Int. Ultrasonics, Ferroelectrics, and Frequency Control Joint 50th Anniversary Conf., 2004, pp. $278-280$.

[12] A. Vorobiev, J. Berge, and S. Gevorgian, "Thin film $\mathrm{Ba}_{0.25} \mathrm{Sr}_{0.75} \mathrm{TiO}_{3}$ voltage tunable capacitors on fused silica substrates for applications in microwave microelectronics," Thin Solid Films, vol. 515, no. 16 pp. 6606-6610, Jun. 2007.

[13] J. Park, J. Lu, S. Stemmer, and R. A. York, "Microwave planar capacitors employing low loss, high- $K$, and tunable BZN thin films," IEEE MTT-S Int. Microw. Symp. Dig., vol. 2, pp. 607-610, Jun. 2005

[14] Y. Shi and S.-G. Kim, "A lateral, self-cleaning, direct contact MEMS switch," in 18th IEEE Int. Conf. on Micro Electro Mechanical Systems 2005, pp. 195-198.

[15] J.-H. Park, H.-C. Lee, Y.-H. Park, Y.-D. Kim, C.-H. Ji, J. Bu, and H.-J. Nam, "A fully wafer-level packaged RF MEMS switch with low actuation voltage using a piezoelectric actuator," J. Micromech. Microeng., vol. 16, pp. 2281-2286, Sep. 2006.

16] R. G. Polcawich, J. S. Pulskamp, D. Judy, P. Ranade, S. TrolierMcKinstry, and M. Dubey, "Surface micromachined microelectro- mechancial ohmic series switch using thin-film piezoelectric actuators," IEEE Trans. Microw. Theory Tech., vol. 55, pp. 2642-2654, Dec. 2007.

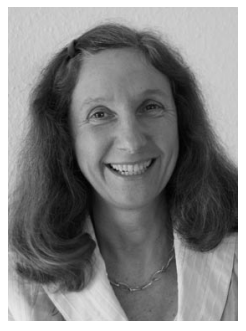

Mareike Klee received her Ph.D. degree from the University of Darmstadt, Germany, in 1984 She then joined Philips Research Laboratories Aachen as a member of the Electronic Ceramics Department and initiated research on inorganic thin films for innovative microelectronic devices, focusing on single oxides as well as complex oxide films. She has built up a technology capability within Philips Research on ferroelectric and piezoelectric thin films that opened the way for several applications comprising the integration of ferroelectric thin-film capacitors with thin-film resistors and ESD diodes in high-K integrated discrete modules. These modules are produced in mass production at NXP Semiconductors. She also developed piezoelectric materials and processes for thin-film ultrasound transducers. Her scientific research resulted in 30 U.S. patents and more than 60 publications, As Research Fellow, she has worked since May 2004 in the System in Package Department of Philips Research Laboratories Eindhoven.

Harry van Esch, Wilco Keur, Biju Kumar, Linda van LeukenPeters, Jin Liu, Rüdiger Mauczok, Kai Neumann, Christel Renders, Marco de Wild, and Jing Zhao biographies and photographs not available at time of publication.

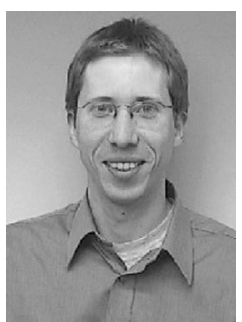

Klaus Reimann (M'03) received his Ph.D. degree from the University of Stuttgart, Germany, in 2002 for research on ordering mechanisms of nanocrystalline intermetallic alloys. He investigated integration technologies for passive components at Philips Research Laboratories in Aachen, Germany (2002-2004), and Eindhoven, The Netherlands (2004-present), including LTCC multilayer substrates, thin-film ferroelectric devices, and MEMS. He continues this research work for NXP semiconductors, formerly known as Philips Semiconductors.

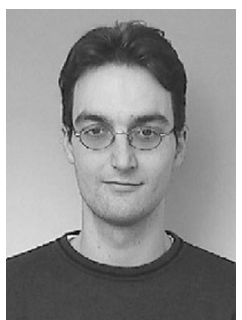

Aarnoud L. Roest received his Ph.D. degree from Utrecht University, the Netherlands, in 2003 for research on the optical and electrical properties of $\mathrm{ZnO}$ quantum dot films. After this, he worked for two years on nanowires made via the laser ablation method for the Technical University Delft, The Netherlands. He investigated integration technologies for passive components at Philips Research Laboratories in Eindhoven (2005-present), including thin-film ferroelectric devices and MEMS. He continues this research work for NXP semiconductors, formerly known as Philips Semiconductors.

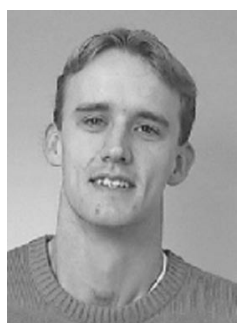

Mark P. J. Tiggelman (M'04) received his electrical engineering degree in telecommunication from the Saxion Higher Technical School (HTS) in Enschede, The Netherlands, in 2002. He graduated in 2005 from the University of Twente (UT) in Enschede with a degree in electrical engineering from the Semiconductor Components group, part of the MESA+ Institute for Nanotechnology. For his master's thesis at the UT, he designed and electrically characterized low-resistance radio fre- 
quency (RF) structures for high- $k$ gate dielectrics with a high leakage current. Currently, he is a Ph.D. student at the Semiconductor Components group of the UT and is detached at NXP Semiconductors Corporate I\&T/Research (Eindhoven, The Netherlands), formally known as Philips Semiconductors. He works on the optimization of ferroelectric materials for microwave frequency agile applications. His primary research interests include electrical characterization, performing simulations, and designing microwave applications.

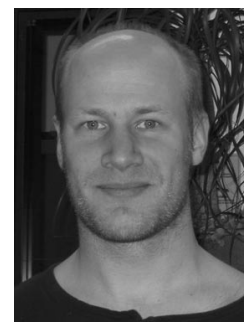

Olaf Wunnicke received his Ph.D. degree from the Technical University of Aachen, Germany, in theoretical solid-state physics. He has investigated the ballistic spin-dependent electron transport in metals and semiconductors with ab-initio methods. During his postdoctoral position at Philips Research, he characterized and modeled semiconducting III-V nanowires. Since then, he has been a researcher at NXP Semiconductors, working on process development, characterization, and modeling of piezoelectric MEMS devices. 